\title{
CONDUTA DE ENFERMEIRAS DIANTE DE CASOS DE VIOLÊNCIA DOMÉSTICA CONTRA A MULHER
}

\author{
NURSES' BEHAVIOR IN CASES OF DOMESTIC \\ VIOLENCE AGAINST WOMEN
}

\section{CONDUCTA DE LAS ENFERMERAS EN CASOS DE VIOLENCIA DOMÉSTICA CONTRA LA MUJER}

\author{
Patrícia de Paula Alves Costa da Silva ${ }^{1}$ \\ Ruth França Cizino da Trindade ${ }^{2}$ \\ Walter Matias Lima ${ }^{3}$
}

\begin{abstract}
Como citar este artigo: Silva PPAC, Trindade RFC, Lima WM. Conduta de enfermeiras diante de casos de violência doméstica contra a mulher. Rev baiana enferm. 2019;33:e33452.

Objetivo: identificar a conduta de enfermeiras inseridas na Estratégia Saúde da Família diante de casos confirmados ou suspeitos de violência doméstica contra a mulher. Método: estudo de natureza qualitativa, realizado em 2012 e 2013, em unidades da Estratégia Saúde da Família, na cidade de Maceió, Alagoas, Brasil, guiado por entrevista semidirigida com 11 enfermeiras, utilizando a análise de conteúdo. Resultados: a violência doméstica contra a mulher é conduzida pelas enfermeiras de diferentes formas, seja por meio de discussão do caso com os demais integrantes da equipe, seja pelo encaminhamento da mulher para outros serviços e profissionais. A maioria das enfermeiras sente-se insegura de prestar assistência às mulheres que sofreram violência. Conclusão: existe uma heterogeneidade na conduta de enfermeiras inseridas na Estratégia Saúde da Família diante de casos confirmados ou suspeitos de violência doméstica contra a mulher, evidenciando que a rede de assistência à saúde da mulher, nesta situação, necessita ser fortalecida.
\end{abstract}

Descritores: Enfermagem. Violência contra a Mulher. Estratégia Saúde da Família.

Objective: to identify the behavior of nurses inserted in the Family Health Strategy in confirmed or suspected cases of domestic violence against women. Method: study of a qualitative nature, carried out in 2012 and 2013, at units of the Family Health Strategy, in the city of Maceió, Alagoas, Brazil, guided by semi-directed interview with 11 nurses, using content analysis. Results: nurses approach the domestic violence against women in different ways, either through discussion of the case with the other team members, either sending women to other services and professionals. Most nurses feel insecure to meet women victims of violence. Conclusion: there is a heterogeneity in the behavior of nurses inserted in the Family Health Strategy in confirmed or suspected cases of domestic violence against women, showing that women's healthcare network, in this situation, needs to be strengthened.

Descriptors: Nursing. Violence against Women. Family Health Strategy.

Objetivo: identificar la conducta de las enfermeras insertadas en la Estrategia de Salud Familiar en casos confirmados o sospechosos de violencia doméstica contra la mujer. Método: estudio de naturaleza cualitativa, llevado a cabo en 2012 y 2013, en las unidades de la Estrategia de Salud Familiar, en la ciudad de Maceió, Alagoas, Brasil, guiado por entrevista semi-dirigida con 11 enfermeras, utilizando análisis de contenido. Resultados: la violencia doméstica

\footnotetext{
Enfermeira. Mestre em Enfermagem. Professora da Universidade Federal de Alagoas Campus Arapiraca. Arapiraca, Alagoas, Brasil. ppalvescosta@hotmail.com. https://orcid.org/0000-0002-9/46-2985

Enfermeira. Doutora em Enfermagem. Mestre em Enfermagem em Saúde Pública. Professora associada da Universidade Federal de Alagoas. Maceió, Alagoas, Brasil. https://orcid.org/0000-000 I-9932-6905

3 Graduado em Filosofia. Doutor em Educação(Filosofia e Educação). Mestre em Filosofia. Professor Associado da Universidade Federal de Alagoas. Maceió, Alagoas, Brasil waltermatias@gmail.com https://orcid.org/0000-000 I-733 I-9475
} 
contra la mujer es llevada a cabo por enfermeras de diferentes maneras, sea a través de la discusión del caso con los otros miembros del equipo, bien como el encaminamiento de mujeres para otros servicios y profesionales. La mayoria de las enfermeras se sienten inseguras para proporcionar asistencia a las mujeres que han sufrido violencia. Conclusión: existe una heterogeneidad en la conducta de las enfermeras insertada en la Estrategia de Salud Familiar en casos confirmados o sospechosos de la violencia doméstica contra las mujeres, mostrando que la red de atención de la salud de la mujer, en esta situación, necesita ser fortalecida.

Descriptores: Enfermería. Violencia Contra la Mujer. Estrategia de Salud Familiar.

\section{Introdução}

O objeto de estudo explorado nesta pesquisa foi a conduta de enfermeiras inseridas na Estratégia Saúde da Família diante de casos de violência doméstica contra a mulher. Este tipo de violência atinge todas as classes sociais, etnias, religiões e culturas, ocorrendo em populações de diferentes níveis de desenvolvimento econômico e social. A Convenção de Belém do Pará/ Organização das Nações Unidas (ONU) conceitua esse fenômeno como todo ato baseado no gênero, que cause morte, dano ou sofrimento físico, sexual ou psicológico à mulher, tanto na esfera pública como privada ${ }^{(1)}$. Gênero é um conceito que possui sua origem nas Ciências Sociais, surgindo enquanto referencial teórico para análise e compreensão da desigualdade entre o que é atribuído à mulher e ao homem. O uso do termo como categoria analítica foi proposto na década de 1970 por historiadoras, como Joan Scott, ligadas ao movimento feminista ${ }^{(1)}$.

No Brasil, nos últimos anos, vem se discutindo os aspectos relacionados à violência doméstica e às diferenças de gênero, tendo a Política Nacional de Enfrentamento à Violência contra as Mulheres como um dos expoentes para diminuição das desigualdades de gênero. Esta política tem por finalidade estabelecer conceitos, princípios, diretrizes e ações de prevenção e combate à violência contra as mulheres, assim como de assistência e garantia de direitos às mulheres em situação de violência, conforme normas e instrumentos internacionais de direitos humanos e legislação nacional. Além disso, está estruturada com base no Plano Nacional de Políticas para as Mulheres (PNPM), elaborado com base na I Conferência Nacional de Políticas para as Mulheres, realizada em 2004 pela Secretaria de Políticas para as Mulheres (SPM) e pelo Conselho Nacional dos Direitos da Mulher (CNDM) ${ }^{(2)}$.

A elaboração da Política Nacional de Enfrentamento à Violência contra as Mulheres pela SPM tem como objetivo explicitar os fundamentos conceituais e políticos do enfrentamento à questão, que têm orientado a formulação e execução das políticas públicas para a prevenção, o combate e o enfrentamento da violência contra as mulheres, assim como para a assistência às mulheres em situação de violência ${ }^{(2)}$.

Diante da dimensão do problema, e em resposta às recomendações ao Estado Brasileiro do Comitê para Eliminação de Todas as Formas de Discriminação contra as Mulheres (CEDAW/ ONU) e da Convenção Interamericana para Prevenir, Punir e Erradicar a Violência contra a Mulher, em 2006, o Brasil passou a contar com a Lei n. $11.340^{(3)}$, chamada de Lei Maria da Penha, específica para coibir a violência doméstica e familiar contra a mulher. Depois dessa lei, os crimes passam a ser julgados nos Juizados Especializados de Violência Doméstica e Familiar contra a Mulher ou, enquanto esses não existirem, nas Varas Criminais. A Lei Maria da Penha, considerada um avanço importante no enfrentamento do problema, representa um passo significativo para assegurar à mulher sua integridade física, psíquica, sexual e moral ${ }^{(2-3)}$.

De acordo com o artigo sétimo da Lei Maria da Penha, violência familiar é aquela que acontece dentro da família, isto é, nas relações entre os membros da comunidade familiar, formada por vínculos de parentesco natural (pai, mãe, filha etc.) ou civil (marido, sogra, padrasto ou 
outros), por afinidade (por exemplo, o primo ou tio do marido) ou afetividade (amigo ou amiga que more na mesma casa). Já a violência doméstica, segundo essa mesma lei, ocorre em casa, no ambiente doméstico ou em uma relação de familiaridade, afetividade ou coabitação ${ }^{(3)}$.

Tendo em vista que a violência afeta significativamente o processo saúde-doença das mulheres, pode-se considerar o setor saúde como locus privilegiado para identificar, assistir e referir as mulheres vitimizadas. Ao longo de suas vidas, as mulheres que vivenciam violência apresentam mais problemas de saúde, geram mais custos de atenção à saúde e buscam, com mais frequência, os serviços hospitalares e de urgência que outras pessoas que não sofrem maus-tratos ${ }^{(4)}$. Nessa direção, a Atenção Básica de Saúde, representada pela Estratégia Saúde da Família (ESF), é reconhecida como um espaço para acolher mulheres em situação de violência, pelo fato de que esse modelo de atenção tem o vínculo como base da relação profissional/usuário e trabalha com adscrição da população no território, favorecendo uma assistência não centralizada no tratamento dos possíveis traumatismos físicos e de suas consequências, mas na sua prevenção primária ${ }^{(5)}$.

Diante do exposto, a violência contra a mulher tem sido um tema mundialmente discutido, sendo crescente o aumento de trabalhos científicos publicados nas últimas décadas. Este fato evidencia que este é um problema a ser explorado, sendo cada vez mais frequente no cotidiano dos serviços de saúde, posto que os profissionais de saúde podem detectar precocemente e intervir, evitando o agravamento do processo e de suas consequências para a saúde da mulher ${ }^{(6-7)}$.

Sendo assim, levando-se em conta que, na ESF, as enfermeiras atuam diretamente na prevenção, promoção e recuperação da saúde e que a violência contra a mulher tem sido responsável pelo adoecimento não apenas da população feminina, como de toda a família, este artigo tem como objetivo identificar a conduta de enfermeiras inseridas na Estratégia Saúde da Família diante de casos confirmados ou suspeitos de violência doméstica contra a mulher.

\section{Método}

Pesquisa descritiva de natureza qualitativa, realizada em Unidades das ESF, na cidade de Maceió, capital do estado de Alagoas, Brasil, cujo protocolo foi aprovado pelo Comitê de Ética em Pesquisa com Seres Humanos da Universidade Federal de Alagoas (CEP/UFAL) sob n. 010304/2009-72.

No momento desta pesquisa, a ESF em Maceió estava composta por 80 equipes de saúde da família distribuídas em 39 Unidades de Saúde da Família (USF) instaladas nas sete regiões distritais desta capital. Estas USF alocavam as equipes de ESF que eram compostas por profissionais médicos(as), enfermeiros(as), auxiliares de enfermagem e agentes comunitários de saúde. A amostra desta pesquisa foi composta por participantes voluntárias, enfermeiras inseridas nas equipes da ESF. Como critérios de inclusão para a escolha das equipes, levaram-se em consideração as características das regiões supracitadas. Uma dessas características diz respeito ao fato de que existem distritos onde as unidades possuem números distintos ou iguais de equipes. Dessa forma, há unidades com uma, duas e até três equipes. Com base nessa distribuição, foram selecionadas duas equipes por distrito com o objetivo de abranger as diversas realidades existentes na cidade.

Para tanto, procedeu-se à seleção das equipes levando em consideração dois aspectos: o primeiro relacionado ao número de equipes por unidade, tendo em vista que UBS com mais equipes representa maior demanda de mulheres usuárias; o segundo aspecto compreendeu a existência de mais de uma UBS com o mesmo número de equipes. Assim, identificadas as UBS que integrariam o estudo, seguiu-se a escolha aleatória por sorteio, o que resultou na seleção de 14 equipes. Como cada equipe possui uma enfermeira, estabeleceu-se que 14 seria o número de participantes dessa categoria profissional. Entretanto, foram realizadas 11 entrevistas, tendo em vista que, no processo de coleta e análise das informações, observou-se que nenhum elemento novo estava sendo acrescido, nas falas 
das enfermeiras, sobre o objeto pesquisado, o que demonstrou não ser necessário prosseguir. Como critérios de exclusão, adotou-se que as profissionais que estivessem de férias ou de licença médica não fariam parte da investigação, sendo substituídas por outras da mesma unidade.

A escolha pela técnica da entrevista semidirigida proporcionou às participantes do estudo momentos preciosos no sentido de construir uma colaboração para dar direção substancial à pesquisa, representando ganho para reunir os dados segundo os objetivos propostos. Para tanto, as perguntas desencadeadoras foram elaboradas de forma a permitir que a entrevistada colocasse livremente o conteúdo de sua resposta. Desta forma, todos os esforços foram alavancados no sentido de melhor construir os momentos de realização do estudo e guiar as entrevistas, num processo empático e gradual de conversação entre pesquisadora e entrevistadas, sendo utilizados os seguintes questionamentos disparadores: Durante seu atendimento, você já suspeitou ou detectou um caso de violência doméstica contra a mulher? Em caso afirmativo, Qual seria a conduta que adotaria diante de um caso suspeito ou confirmado deste tipo de violência?

O conceito escolhido para esta pesquisa com relação ao termo conduta, no âmbito das compreensões existentes na área da saúde, foi o que consta na Biblioteca Virtual de Saúde (BVS), em seu descritor intitulado "conduta", que afirma ser a resposta observável de uma pessoa diante de qualquer situação. Considerando-se uma conceituação mais abrangente, o dicionário define essa expressão como a "maneira de alguém se conduzir, se comportar; procedimento" ${ }^{(8: 204)}$. Embora ambas as definições contemplem o sentido que se pretendeu adotar nesta pesquisa, o significado extraído do dicionário é o que se aproxima daquele que o termo possui neste estudo. Assim, entende-se como conduta, neste estudo, a maneira como as enfermeiras conduzem-se e/ou procedem diante de casos suspeitos ou confirmados de violência doméstica contra a mulher.

As informações foram coletadas por meio de entrevistas registradas em gravação, durante o segundo semestre de 2013. As enfermeiras que participaram do estudo foram previamente contatadas, algumas por telefone, outras em visita à unidade, momento em que se fazia o convite para participar do estudo e marcar hora e local da entrevista. Nos dias de realização das entrevistas, a pesquisadora dirigia-se ao encontro das participantes nos próprios serviços em que trabalhavam. Ressalta-se que, para manter o sigilo sobre a identidade das enfermeiras, as unidades não foram identificadas e todas as entrevistadas foram identificadas pela expressão "Enfermeira" seguida de um numeral que identificava a ordem da entrevista. As profissionais foram informadas e esclarecidas quanto aos aspectos éticos da Resolução CNS n. 466, de 2012, relacionados no Termo de Consentimento Livre e Esclarecidos (TCLE), e assinaram-no em duas vias: uma foi-lhes entregue, e a outra ficou com a pesquisadora.

Após as entrevistas, procedeu-se à escuta e transcrição cuidadosas, organizadas, buscando encontrar núcleos de sentido, que, sendo aproximados, originaram as categorias e respectivas subcategorias. A escuta, transcrição e leitura das entrevistas permitiram uma aproximação e convergências das falas das entrevistadas. Os dados foram submetidos à análise de conteúdo categorial ${ }^{(9)}$.

O referencial teórico-metodológico que subsidiou a análise dos temas selecionados e das respectivas categorias foi a técnica de Análise de Conteúdo, especificamente a Análise Temática, que pode ser traduzida em uma técnica que procura, nas expressões verbais ou textuais, os temas gerais recorrentes e ou relevantes, após leituras minuciosas dos registros de entrevista e de observação ${ }^{(9)}$. Sendo assim, após as leituras de assimilação, utilizando critérios de relevância e de repetição, conforme o referencial teórico-metodológico desta pesquisa, emergiram duas categorias que serão apresentadas nos resultados.

\section{Resultados}

Participaram do estudo somente profissionais do sexo feminino que atuavam nas equipes de ESF, visto que não foi encontrado nenhum do sexo masculino nos serviços contatados. Com 
relação à caracterização das participantes do estudo, a média de idade é de 41 anos, a maioria tem mais de 15 anos de formação e 11 anos de experiência profissional na ESF. Merece ser destacado o fato de todas as entrevistadas terem feito algum curso de especialização na área de saúde pública, saúde coletiva ou saúde da família. Duas enfermeiras relataram ter visto o tema sobre violência contra a mulher na graduação.

Os resultados mostraram que a violência doméstica contra a mulher, a exemplo da perpetrada por parceiro íntimo, encontra-se no cotidiano do trabalho das enfermeiras em suas diversas formas de manifestação. Entretanto, apesar desta realidade, a instituição não as prepara para agir de forma propositiva junto às mulheres violentadas, constatando-se que isto pode levá-las a adotarem condutas distintas em casos suspeitos ou mesmo confirmados, como foi evidenciado neste estudo. Dessa forma, os relatos das enfermeiras entrevistadas evidenciaram duas categorias de análise que revelaram os tipos de condutas adotados quando se tratava de atendimento de mulheres em situação de violência: a primeira, refere-se às condutas das enfermeiras diante de casos suspeitos ou confirmados de violência contra a mulher; a segunda, alude às limitações e inadequações do saber instrumental e dos serviços.

\section{Condutas das enfermeiras diante de casos suspeitos ou confirmados de violência contra a mulher}

Após as análises das respostas das entrevistas, pôde-se identificar que as posturas relativas às condutas adotadas pelas enfermeiras da ESF no atendimento à mulher em situação de violência doméstica foram diversas. Esta heterogeneidade na condução das situações de violência, na maioria dos serviços pesquisados, pode estar relacionada à ausência de um protocolo que direcione a atuação dessas profissionais no atendimento à mulher em situação de violência, isto é, que oriente e norteie a conduta a ser adotada.

A análise dos relatos revelou que algumas enfermeiras, quando detectavam situação de violência sofrida pela mulher, adotavam a conduta de compartilhar o caso, para que a equipe da unidade tomasse conhecimento:

[...] ela [a vítima] chamou para a gente conversar na área da grota e se apresentou, contou o caso. E aí a gente pede ajuda a assistente social. (Enfermeira 6).

Outros depoimentos revelaram que as enfermeiras encaminhariam o caso para os órgãos tidos como responsáveis em assistir a mulher em situação de violência, isto é, o enfermeiro transferia a competência para outros serviços:

Tem a Delegacia da Mulher que é lá no Centro e nem sei se ainda é [...] Eu acho que é delegacia mesmo, de caso policial. (Enfermeira 5).

Eu orientava o que ela deveria fazer: procurava a Delegacia da Mulher, a questão da própria denúncia, denunciar o parceiro. (Enfermeira 8).

Além de citarem a Delegacia da Mulher como serviço de referência para dar seguimento aos casos de violência doméstica contra a mulher, outras entrevistadas citaram ainda outro tipo de serviço para onde as encaminhavam:

\footnotetext{
É essa [Casa abrigo Dra. Terezinha Ramires] que eu lembro bem, porque foi colocado [na palestra em que participou pela Secretaria Municipal de Saúde de Maceió] [...], mas eu sei, porque a gente teve não uma capacitação, mas uma palestra [...] (Enfermeira 6).
}

Eu orientei que tinha que ir para o Pam Salgadinho. (Enfermeira 1).

Com relação às condutas que adotariam diante da suspeita de caso de violência, tendo a mulher vivido esta situação, a Enfermeira 7 demonstrou preocupação com esses casos, ao afirmar que se empenharia em buscar apoio, mas, ao mesmo tempo, mostrava desconhecimento de como deveria conduzir o caso, sendo enfermeira da ESF:

\footnotetext{
Se acontecesse agora de surgir uma situação problema [algum caso de violência doméstica contra a mulher] eu iria correr atrás; ia atrás procurar com alguma colega. Se eu não conseguisse, iria pra outro [colega]. O mesmo quando surge algo que a gente não tá habituado a lidar todo dia.
}

Nas unidades que dispunham de assistente social, todas as profissionais relataram que, caso identificassem em seu atendimento/consulta algo sugestivo de uma mulher que estava em situação de violência, fariam um encaminhamento para essa profissional. Assim, mais uma vez, identificou-se que a conduta do enfermeiro 
em relação à mulher em situação de violência estava relacionada a transferir competência:

A gente tem aqui uma assistente social, que qualquer problema [...] a gente não se acha apta a resolver. A gente passa pra ela e ela procura o serviço. (Enfermeira 2).

[...] a gente procura a assistente social aqui do posto. Ai eu sei que realmente ela já deu essa orientação, mas a gente não conbece, não, outros caminhos. (Enfermeira 3).

O trecho acima torna notório que a enfermeira não desenvolveria uma conduta assistencial direta com a possível vítima, pois não se considerava preparada para atuar no contexto de violência em que a mulher encontrava-se inserida. Desse modo, a enfermeira recorreu a outra profissional, a assistente social, para que desse seguimento ao caso. Nessas unidades que dispunham de assistente social, as enfermeiras afirmaram desconhecer outros meios de conduta, senão o de levar o caso para essa profissional. Um aspecto que também se destaca na fala acima é a generalização, ao ser utilizado o termo "a gente" em vez de "eu".

Vale ressaltar que boa parte das equipes de saúde da família conta apenas com as categorias que compõem a equipe básica: médico, enfermeira, auxiliar/técnico de enfermagem e o agente comunitário de saúde. Nas equipes que não contavam com a presença da assistente social, os profissionais relataram que abordariam a vítima no sentido de prestar-lhe apoio emocional e encaminhá-la para órgãos responsáveis por essa temática.

[...] numa situação emergencial [de violência doméstica contra a mulher] o que poderia fazer era ligar para a Saúde da Mulber [Secretaria Municipal]. Eu lembro que tinha um encaminhamento que a gente fazia para a Santa Mônica. Inclusive, eles disseram [na capacitação que fez sobre violência contra a mulher há mais ou menos três anos] que, em casos assim [de violência], não fizesse nada, orientasse a pessoa a procurar o serviço [Santa Mônica] que lá eles fazem tudo: o procedimento de orientação, diagnóstico, de captação também, de prevenção de DST, toda a abordagem. Até anotei o número. Acho que devo ter na agenda. (Enfermeira 7).

As enfermeiras continuavam adotando a conduta de encaminhar a mulher para outro profissional lidar com a situação, mesmo se colocando como mediadoras. Assim, o psicólogo foi citado como o profissional capaz de dar apoio às mulheres.
[...] tentaria puxar dela se estaria acontecendo alguma coisa, encaminharia para um psicólogo da própria unidade, mas eu creio que eu a orientaria assim: primeiro ao psicólogo, para ela ser orientada da melhor forma, ser orientada para tomar as condutas mais plausiveis para tentar sair daquele meio. Primeiramente eu acho que iria para o psicólogo, para ele tentar puxar dela alguma coisa. (Enfermeira 8).

\section{Limitações e inadequações do saber} instrumental e dos serviços

Apesar de todos os esforços na tentativa de adotar uma conduta favorável no atendimento à mulher, todas as enfermeiras deste estudo relataram dificuldades de lidar com a situação. Entre os problemas relatados neste estudo, foram citados: insuficiência de equipamentos e serviços, carência de pessoal e concentração de serviços na capital. Embora exista uma Secretaria de Estado da Mulher, da Cidadania e dos Direitos Humanos no município, são quase inexistentes estruturas específicas para tratar do tema e, quando há, em geral, estão vinculadas a alguma Coordenação.

Diversas justificativas foram dadas para não haver a devida continuidade de atendimento à mulher em situação de violência. Dentre essas, estão, principalmente, o medo de se expor, não consentimento para intervir, insegurança e despreparo na condução.

Honestamente, eu não sei. Eu sei o que eu deveria fazer - que seria denunciar -, mas, bonestamente, eu não sei porque. Eu moro aqui [cita o nome do lugar, que fica próximo da Unidade em que trabalha], eu teria medo por mim depois. Eu não sei qual é a índole dessa pessoa [o agressor]. Vai que eu denuncio e acaba sobrando pra mim. Entendeu? (Enfermeira 5).

E eu vou fazer o quê? E eu tenho até medo! Eu vou falar alguma coisa pra o marido dela ir lá saber de mim o que é que eu estou falando [incentivando a denunciar] com a mulber dele? (Enfermeira 8).

Diante das subjetividades e fragilidades com relação ao tema aqui explorado, a totalidade das entrevistadas concluiu sua participação registrando que sentia a imensa necessidade de ser capacitada para lidar com as questões de violência doméstica contra mulher, apesar do medo registrado por algumas, visto que não se sentiam preparadas ou faltava-lhes apoio dos órgãos aos quais estavam diretamente atreladas. 
A gente disse que precisava de apoio, suporte... Ahb!... Liguei... Chamava, chamava e não atendia [...] eu fui tentando outros ramais da Secretaria, mas não obtive êxito. (Enfermeira 1).

A gente tem a saúde da mulher que está mais ligado ao pré-natal, citologia, essas coisas assim. Não sei se eles [da Secretaria Municipal de Saúde] têm na saúde da mulher, onde eu deveria procurar essa informação [sobre a violêncial entendeu? (Enfermeira 2).

Mas eu acho que a gente precisa de apoio, eu não estaria segura. Iria chamar a direção, iria chamar a assistente social, se a mulher permitisse. Mas a gente ainda fica muito... A coisa é muito frouxa ainda, não tem nada amarrado. (Enfermeira 3).

\section{Discussão}

Atender mulheres que sofrem de violência é zelar pelos direitos humanos e valorizar, no espaço da saúde, onde se encontra a ESF, a sua realização. A defesa desses direitos perpassa pelo compromisso de enfermeiras e enfermeiros, que, no cotidiano dos serviços de saúde e espaços sociais, lutam para promover a diminuição das desigualdades que dificultam o acesso aos serviços e ao cuidado à saúde de qualidade ${ }^{(5,10)}$.

Acredita-se que esses profissionais atuantes nas equipes da ESF, pela ampla cobertura e vínculo que estabelecem com as famílias, possam ser eficientes aliados. Isso porque atuam tanto na USF quanto no domicílio e, nesse contato, conhecem a intimidade dos lares, o que facilita o reconhecimento e a tomada de providências nos casos de violência doméstica contra a mulher ${ }^{(11)}$.

Um estudo, cujo objetivo foi conhecer as estratégias utilizadas por enfermeiros de Unidades de ESF para identificação e enfrentamento de situação de violência por parceiro íntimo em mulheres gestantes, revelou que a violência contra a mulher foi caracterizada como um problema sério e importante na sociedade, tendo como causa e consequência a desigualdade de gênero. Dessa forma, na prática profissional, aponta-se a necessidade de organização de um protocolo de enfermagem que auxilie na identificação e classificação de risco à exposição à violência, educação permanente desses profissionais e fortalecimento das ações intersetoriais ${ }^{(12)}$.

Dentre todas as unidades da ESF incluídas neste estudo, apenas em uma delas identificou-se a presença de um cartaz com o protocolo de encaminhamento para as mulheres vítimas de violência, afixado em mural informativo para os usuários. Esta situação sugere que é necessária a ampla divulgação de informações, a exemplo de cartazes com protocolo de direcionamento dos casos de violência, para auxiliar os profissionais e as mulheres em situação de violência que necessitam de informações quanto aos mecanismos e procedimentos existentes. Não foi identificado, em nenhum relato, o protocolo de notificação de violência como uma conduta a ser realizada pelo enfermeiro, ao identificar a vivência de uma situação de violência.

O protocolo encontrado na unidade referida acima cita um dos locais para onde a mulher vítima de violência deve ser encaminhada. Trata-se do Centro de Atendimento e Referência às Mulheres Vítimas de Violência Doméstica Dra. Terezinha Ramires, inaugurado em 8 de março de 2002, instalado em um Posto de Atendimento Médico (PAM) vinculado à Secretaria de Saúde de Maceió, o qual forneceu equipe técnica da instituição, que conta com quatro psicólogas, três assistentes sociais e três auxiliares administrativos. Esse Centro, concretizado pela Lei $\mathrm{n}^{\mathrm{o}}$ 4. 446, de setembro de 1995, surgiu em consequência da luta do movimento feminista e de mulheres alagoanas, tendo como autora a então vereadora Terezinha Ramires. Essa lei prevê a criação de um Centro de Referência e de uma Casa Abrigo para atenderem mulheres vítimas de violência, os quais representam um grande avanço, não só na cidade de Maceió como em todo o estado de Alagoas, no enfrentamento da violência de gênero ${ }^{(13)}$.

Por outro lado, as enfermeiras desta pesquisa relataram que, ao se depararem com a demora na resolutividade, mesmo quando adotavam a conduta de encaminhar os casos de violência para os serviços disponíveis, identificavam a fragilidade da rede de serviços no setor da saúde e da justiça. Apesar de estar prevista em lei a criação de locais de apoio às mulheres violentadas, estes encontravam-se superlotados, fato que contribuía ainda mais para o aumento e a invisibilidade dos casos. Isso acabava colocando 
as mulheres em uma posição de vulnerabilidade nas relações de gênero ${ }^{(14-15)}$.

Como se não bastasse a demora no feedback dos encaminhamentos feitos pelas enfermeiras, as mulheres em situação de violência também percebiam a falta de adequação na assistência recebida nos serviços aos quais foram encaminhadas, fato mencionado pelas enfermeiras deste estudo. Constatam-se, assim, dificuldades de capacitação profissional como um fator motivador para isso. O despreparo profissional ou ausência de qualificação em serviço reflete-se diretamente nas ações de atendimento às mulheres com essa problemática, impactando no não reconhecimento da violência que acomete muitas daquelas que procuram o serviço ${ }^{(5,16)}$.

Outra pesquisa, cujo objetivo era analisar a estrutura e os conteúdos das representações sociais de enfermeiras acerca da violência doméstica contra a mulher, mostra que, arraigada à memória coletiva, a agressão física carrega significados para a prática profissional, visto ser a forma mais comum de reconhecimento das enfermeiras de uma mulher nesta situação. Diante dessa visão, a assistência pode priorizar o tratamento de lesões, sem contemplar a subjetividade das mulheres, o que pode ser uma barreira para a atuação no atendimento de mulheres em situação de risco ${ }^{(11,17)}$.

A enfermeira ou qualquer outra categoria profissional possui seu modo de entender a violência e prestará assistência à mulher agredida com base em sua concepção. No tocante a isso, o despreparo, associado ao peso para lidar com as histórias de violência, gera dilemas e contradições, limitando, nesse contexto, as ações de cuidado. Portanto, a abordagem desse fenômeno é permeada por crenças, julgamentos e estereótipos entre os profissionais da saúde, inibindo um atendimento eficaz e humanizado das mulheres vitimadas ${ }^{(18)}$.

Com relação à inibição no atendimento, a maioria das participantes deste estudo adotou como conduta encaminhar as situações de violência contra a mulher para outros profissionais, como a assistente social e a psicóloga. Acreditavam que tais profissionais, principalmente as psicólogas, possuíam maior afinidade com o tema e, por essa razão, assistiriam a mulher em suas emoções e fragilidades diante da situação vivenciada.

Neste contexto, porém, os profissionais da área da enfermagem são os que realizam, na maioria das vezes, o primeiro atendimento às mulheres em situação de violência nos diversos níveis da rede de atenção à saúde. Assim, precisariam estar qualificados no que se refere ao acolhimento das necessidades multidimensionais e das demandas intersetoriais dessas mulheres. Isso requer que as enfermeiras possam reconhecer as dimensões de nível relacional e social, que solicitam considerar também as questões de gênero, de raça/etnia e de geração ${ }^{(19-20)}$.

Sabe-se que os profissionais de saúde são de grande valia na identificação de indivíduos e grupos populacionais de risco para a violência e na execução de iniciativas que promovam a prevenção e as intervenções mais adequadas. Isso é importante, pois, a cada dia, aumenta a necessidade de atendimento às mulheres em situação de violência que chegam aos serviços de saúde ${ }^{(21)}$.

Neste estudo, os relatos corroboraram as pesquisas citadas, pois as enfermeiras perceberam que é crescente o número de mulheres que procuram os serviços em que trabalham, tendo, inclusive, histórico de violência por parceiro íntimo. Salienta-se, por exemplo, a passagem das mulheres agredidas pelos centros de acolhimento à mulher violentada, a partir da conduta da enfermeira de encaminhá-la para esses locais e até tentar conduzir o caso através da ficha de notificação da violência sofrida, apesar de não a conhecer.

Uma pesquisa realizada com 35 profissionais de saúde, incluindo enfermeiras, em 20 USF em Salvador, Bahia, Brasil, objetivou identificar a relação entre formação profissional e notificação da violência contra a mulher na ESF. Os resultados demonstraram que a temática violência contra a mulher não foi abordada na graduação e/ou pós-graduação da maioria dos profissionais; para os demais, a abordagem deu-se de forma superficial e pontual. Com relação à educação 
em serviço, o estudo revelou que a temática não é foco de discussão em capacitações nem reuniões. Concluiu-se que é estreita a relação entre a abordagem da temática violência contra a mulher nos espaços de formação acadêmica, bem como em serviço, e a notificação do agravo ${ }^{(22-23)}$.

As enfermeiras deste estudo também se ressentiam da falta de capacitação e apoio. Apesar do grave impacto da violência à saúde física e mental de mulheres, ainda há resistência e necessidade de maior preparo das enfermeiras incluídas para abordar situações de violência doméstica no âmbito do sistema de saúde.

Ao serem instrumentalizadas sobre a temática, suas dimensões, seus conceitos, sua magnitude e a maneira de identificar e saber cuidar de mulheres que vivenciam a violência doméstica, as enfermeiras poderão auxiliar na minimização de possíveis agravos à condição de saúde da mulher ${ }^{(18-19)}$. No caso da enfermagem (campo de saber), na relação com mulheres que vivenciam a violência doméstica, precisam criar condições para que possam constituir e articular seu mundo interno com a demanda externa, reparando a experiência de dor, para que essa mulher possa, a partir dessa experiência, desenvolver novas formas de ser e agir no mundo, para que lhe seja oportunizado "um novo começo", isto é, uma reconexão com o prazer, com o amor e a vida.

\section{Conclusão}

Neste estudo, os resultados mostraram que a violência doméstica contra a mulher encontra-se no cotidiano de trabalho das enfermeiras e é identificada por estas em suas diversas formas de manifestação. Todavia, apesar dessa realidade, constatou-se que as condutas adotadas foram distintas. Entende-se, dessa forma, que a violência doméstica contra a mulher deve ser vista como uma questão de saúde pública que precisa de intervenções sedimentadas, isto é, de políticas públicas específicas. A ESF, local de estudo desta pesquisa, por exemplo, deve ser vislumbrada como um modelo de assistência à saúde que tem grande potencial para o combate dessa problemática.
Espera-se oportunizar a discussão em torno dos resultados desta pesquisa, contribuindo para a prevenção de violência doméstica contra a mulher, a ampliação de estratégias políticas e amplas campanhas em âmbito nacional, para a prevenção e o controle voltados para o tema, dentre outros.

Acredita-se que os resultados desta pesquisa podem contribuir para refletir sobre o processo de trabalho de enfermeiros com relação à temática deste estudo. Para tanto, a incorporação do tema nos currículos escolares, nas unidades de saúde, com discussões multidisciplinares voltadas para análise e acompanhamento dos casos atendidos, o contínuo incentivo às pesquisas e consequentes produções sobre o assunto, assim como o trabalho interdisciplinar com os profissionais envolvidos com o tema, levam à sensibilização e à atenção para a temática da violência doméstica contra a mulher.

\section{Colaborações:}

1 - concepção, projeto, análise e interpretação dos dados: Patrícia de Paula Alves Costa da Silva e Ruth França Cizino da Trindad;

2 - redação do artigo e revisão crítica relevante do conteúdo intelectual: Patrícia de Paula Alves Costa da Silva, Ruth França Cizino da Trindade e Walter Matias Lima;

3 - aprovação final da versão a ser publicada: Patrícia de Paula Alves Costa da Silva.

\section{Referências}

1. Brasil. Ministério da Saúde. Secretaria de Atenção à Saúde. Departamento de Ações Programáticas Estratégicas. Atenção integral para mulheres e adolescentes em situação de violência doméstica e sexual: matriz pedagógica para formação de redes. Brasília (DF); 2011.

2. Brasil. Presidência da República. Secretaria de Políticas para as Mulheres. Secretaria Nacional de Enfrentamento à Violência Contra as Mulheres. Política Nacional de Enfrentamento à Violência Contra as Mulheres [Internet]. Brasília (DF); 2011 [cited 2019 Oct 28]. Available from: https://www12.senado.leg.br/institucional/omv/ 
entenda-a-violencia/pdfs/politica-nacional-deenfrentamento-a-violencia-contra-as-mulheres

3. Brasil. Presidência da República. Lei n. 11.340, de 7 de agosto de 2006. Cria mecanismos para coibir a violência doméstica e familiar contra a mulher, nos termos do $₫ 8^{\circ}$ do art. 226 da Constituição Federal, da Convenção sobre a Eliminação de Todas as Formas de Discriminação contra as Mulheres e da Convenção Interamericana para Prevenir, Punir e Erradicar a Violência contra a Mulher; dispõe sobre a criação dos Juizados de Violência Doméstica e Familiar contra a Mulher; altera o Código de Processo Penal, o Código Penal e a Lei de Execução Penal; e dá outras providências [Internet]. Brasília (DF); 2006 [cited 2019 Nov 5]. Available from: http://www.planalto.gov.br/ ccivil_03/_ato2004-2006/2006/lei/111340.htm

4. Organização Pan-americana de Saúde. Informe mundial sobre la violencia y la salud: resumen [Internet]. Washington (DC); 2002 [cited 2019 Nov 3]. Available from: http://www.who.int/violence_ injury_prevention/violence/world_report/es/ summary_es.pdf

5. Martins LCA, Silva EB, Dilélio AS, Costa MC, Colomé ICS, Arboit J. Violência de gênero: conhecimento e conduta dos profissionais da estratégia saúde da família. Rev Gaúcha Enferm [Online]. 2018 Jul;39:e2017-0030. DOI: 10.1590/1983-1447.2018.2017-0030

6. Albuquerque Netto L, Moura MAV, Queiroz ABA, Leite FMC, Silva GF. Isolamento de mulheres em situação de violência. Escola Anna Nery [Online]. 2017 Jan;21(1):e20170007. DOI: $10.5935 / 1414-8145.20170007$

7. Silva PPAC. Conduta de enfermeiras da estratégia saúde da família diante de casos de violência familiar contra a mulher [dissertação]. Maceió: Universidade Federal de Alagoas; 2014.

8. Ferreira ABH. Novo dicionário Aurélio da língua portuguesa. 4a ed. Curitiba: Positivo; 2009.

9. Minayo MCS. O desafio do conhecimento: pesquisa qualitativa em saúde. 8 a ed. São Paulo: Hucitec; 2004.

10. Cortes LF, Padoin SMM, Vieira LB, Landerdahl MC, Arboit J. Cuidar mulheres em situação de violência: empoderamento da enfermagem em busca de equidade de gênero. Rev Gaúcha Enferm [Online]. 2015;36(esp):77-84. DOI: 10.1590/1983-1447.2015. esp. 57162
11. Acosta DF, Gomes VLO, Oliveira DC, Marques SC, Fonseca AD. Representações sociais de enfermeiras acerca da violência doméstica contra a mulher: estudo com abordagem estrutural. Rev Gaúcha Enferm [Online]. 2018;39:e61308. DOI: https://doi. org/10.1590/1983-1447.2018.61308

12. Marques SS, Riquinho DL, Santos MC, Vieira LB. Estratégias para identificação e enfrentamento de situação de violência por parceiro íntimo em mulheres gestantes. Rev Gaúcha Enferm [Online]. 2017;38(3):e67593. DOI: http://dx.doi. org/10.1590/1983- 1447.2017.03.67593

13. Alagoas. Secretaria Especializada da Mulher. Nunca é tarde demais para se conhecer. Maceió: Imprensa Oficial e Gráfica Graciliano Ramos; 2005.

14. Minayo MCS. Violência e saúde. Rio de Janeiro: Fiocruz; 2006.

15. Macy RJ, Martin S, Nwabuzor Ogbonnaya I, Rizo CF. What do domestic violence and sexual assault service providers need to know about survivors to deliver services? Violence Against Women. 2018 Jan;24(1):28-44. DOI: $10.1177 / 1077801216671222$

16. Gomes VLO, Silva CD, Oliveira DC, Acosta DF, Amarijo CL. Domestic violence against women: representations of health professionals. Rev Latino-Am Enfermagem. 2015 Jul-Aug;23(4):718-24. DOI: $10.1590 / 0104-1169.0166 .2608$

17. O'Reilly R, Peters K. Opportunistic domestic violence screening for pregnant and post-partum women by community based health care providers. BMC Womens Health. 2018 Jul;18(1):128. DOI: 10.1186/s12905-018-0620-2

18. Acosta DF, Gomes VLO, Oliveira DC, Gomes GC, Fonseca AD. Aspectos éticos e legais no cuidado de enfermagem às vítimas de violência doméstica. Texto Contexto-Enferm. 2017;26(3):e6770015. DOI: 10.1590/0104-07072017006770015

19. Vieira LB, Cortes LF, Padoin SMM, Souza IEO, Paula CC, Terra MG. Abuso de álcool e drogas e violência contra as mulheres: denúncias de vividos. Rev bras enferm. 2014 June;67(3):366-72. DOI: $10.5935 / 0034-7167.20140048$

20. Brasil. Ministério da Saúde. Secretaria de Atenção à Saúde. Departamento de Ações Programáticas Estratégicas. Prevenção e tratamento dos agravos resultantes da violência sexual contra mulheres e adolescentes: norma técnica. 3a ed. atual. e ampl. Brasília; 2012. 
21. Santos J, Andrade RL, Reis LA, Duarte SFP. Conhecimento de enfermeiras em unidades de saúde sobre a assistência à mulher vítima da violência. Rev baiana enferm. 2014 Set;28(3):260-70. DOI: http://dx.doi.org/10.18471/rbe.v28i3.9255

22. Cordeiro KCC, Santos RM, Gomes NP, Melo DS, Mota RS, Couto TM. Formação profissional e notificação da violência contra a mulher. Rev baiana enferm. 2015 Jul;29(3):209-17. DOI: http:// dx.doi.org/10.18471/rbe.v29i3.13029
23. Moazen B, Salehi A, Soroush M, Molavi Vardanjani $\mathrm{H}$, Zarrinhaghighi A. Domestic violence against women in Shiraz, Southwestern Iran. J Inj Violence Res. 2019 Jul;11(2):243-54. DOI: 10.5249/jivr. v11i2.1238

Recebido: 7 de setembro de 2019

Aprovado: 19 de novembro de 2019

Publicado: 11 de março de 2020

A Revista Baiana de Enfermagem utiliza a Licença Creative Commons - Atribuição-NãoComercial 4.0 Internacional. https://creativecommons.org/licenses/by-nc/4.0/ Este artigo é de acesso aberto distribuído sob os termos da Licença Creative Commons (CC BY-NC). Esta licença permite que outros remixem, adaptem e criem a partir do seu trabalho para fins não comerciais. Embora os novos trabalhos tenham de lhe atribuir o devido crédito e não possam ser usados para fins comerciais, os usuários não têm de licenciar esses trabalhos derivados sob os mesmos termos. 